\title{
Molluscicidal activity of Hammada scoparia (Pomel) Iljin leaf extracts and the principal alkaloids isolated from them against Galba truncatula
}

\author{
R Mezghani-Jarraya', H Hammami², A Ayadi²+, M Damak ${ }^{1}$ \\ ${ }^{1}$ Laboratory of Natural Substances Chemistry, Faculty of Science, Sfax, Tunisia ${ }^{2} F u n g a l$ and Parasitic Molecular Biology Laboratory, \\ Faculty of Medicine, Sfax, Tunisia
}

The molluscicidal activity of Hammada scoparia leaf extracts and the principal alkaloids isolated from them (carnegine and $\mathrm{N}$-methylisosalsoline) were tested against the mollusc gastropod, Galba truncatula, the intermediate host of Fasciola hepatica in Tunisia. The results indicated that the molluscicidal activity was correlated with the presence of alkaloids. A significant molluscicidal value, according to the World Health Organization, was found with the methanol extract $\left(L C_{50}=28.93 \mathrm{ppm}\right)$. Further fractionation of the methanolic extract led to the isolation of two principal alkaloids: carnegine and N-methylisosalsoline. These alkaloids are isoquinolines that have not previously been characterised for their molluscicidal activity. The N-methylisosalsoline possesses the highest molluscicidal activity $\left(L C_{50}=0.47 \mu M\right.$ against $\mathrm{G}$. truncatula).

Key words: molluscicidal activity - Galba truncatula - Fasciola hepatica - Hammada scoparia - major alkaloids - $N$-methylisosalsoline

Fasciolosis, caused by Fasciola hepatica, a parasitic trematode, is of considerable medical and veterinarian importance. This old disease can spread widely because of the large colonisation capacity of the parasite, as well as of the freshwater lymnaeid snail vector species (MasComa et al. 2001). Galba truncatula (Lymnaeidae family) has been identified as the principal intermediate host of F. hepatica in Southern Tunisia (Ayadi et al. 1997, Hammami \& Ayadi 1999, Hammami et al. 2007). One of the major preventive steps against fasciolosis is the control of the vector snail population. Use of molluscicides to eradicate the snail vector is considered the method of choice. Plants containing alkaloids appear to be among the most promising for controlling schistosomiasis and fasciolosis (Melendez \& Capriles 2002, El-Ansary et al. 2003, Ahmed \& Rifaat 2004, Silva et al. 2006).

Since Hammada scoparia (Chenopodiaceae family) has been described as a plant rich in alkaloids (Carling \& Sandberg 1970, Benkrief et al. 1990, Jarraya et al. 1993, 2008, Jarraya \& Damak 2001), we designed the present study to assess the molluscicidal activity of $H$. scoparia leaf extracts and the principal alkaloids isolated from them against the mollusc gastropod, G. truncatula.

H. scoparia (Pomel) Iljin $=($ Haloxylon scoparium (Pomel) Bge. $=$ Haloxylon articulatum ssp scorparium $($ Pomel) Batt. $=$ Arthrophytum scoparium (Pomel) Iljin) belongs to Chenopodiaceae family and is locally known as rimth in Sfax, Tunisia. Samples of this plant were collected

Financial support: Ministry of Higher Education, Scientific Researches and Technology, Tunisia

+ Corresponding author: ali.ayadi@rns.tn

RM-J and $\mathrm{HH}$ are co-authors.

Received 18 July 2009

Accepted 7 October 2009 in June 2006 in Sfax, Tunisia and botanically identified by Pr. Mohamed Chaeib, Botanist at the faculty of Science Sfax. Voucher specimens (LCSN101) have been deposited at the Laboratoire de Chimie des Substances Naturelles, Faculty of Science, University of Sfax, Tunisia.

Extracts of air-dried leaves of $H$. scoparia were prepared by two methods. For the first method, $300 \mathrm{~g}$ of air-dried leaves were extracted with $10 \%$ ethanol in water for $48 \mathrm{~h}$ at RT. The ethanol was removed and the remaining aqueous phase was lyophilised to produce the EtOH- $\mathrm{H}_{2} \mathrm{O}$ extract $(40.52 \mathrm{~g})$.

For the second method, $200 \mathrm{~g}$ of air-dried leaves of $H$. scoparia were extracted (for $24 \mathrm{~h}$ each time) in a Soxhlet apparatus with hexane, dichloromethane and methanol, in succession. Each extract was concentrated to produce the hexane extract (HE, $2.10 \mathrm{~g}$ ), the dichloromethane extract (DE, $4.55 \mathrm{~g}$ ) and the methanol extract (ME, 30.15 g), respectively. Each extract was weighed and kept in a refrigerator at $4^{\circ} \mathrm{C}$ until use. A sample of each extract was tested for the presence of alkaloids using Mayer's and Dragendorf's reagents.

An acid-base treatment of the methanol extract was performed as follows: $20 \mathrm{~g}$ of the methanol extract were dissolved in hydrochloric acid $(0.05 \mathrm{M})$ and then extracted three times with chloroform. After removing and evaporating the chloroform we obtained extract A $(1.66 \mathrm{~g})$. The remaining aqueous layer was alkalinised, adjusted to $\mathrm{pH}=9$ by the addition of ammonia solution $28 \%$, then extracted three times with chloroform. After removing and evaporating the chloroform, we obtained extract B (5 g), containing total alkaloids. Finally, the remaining aqueous layer was extracted three times with butanol. After removing and evaporating the butanol we obtained extract $\mathrm{C}(3.35 \mathrm{~g})$ containing polar products.

Extract B (5 g) was loaded on a silica gel column (Merck, 230-400 mesh) and eluted with a gradient of chloroform/methanol (100:0 $\rightarrow$ 0:100). Eleven fractions were collected. Two fractions contained the pure 
alkaloids: carnegine $1(1050 \mathrm{mg})$ and $N$-methylisosalsoline $2(545 \mathrm{mg})$, previously isolated from H. scoparia (Carling \& Sandberg 1970, Benkrief et al. 1990, Jarraya \& Damak 2001, Jarraya et al. 2008). The configuration of the chiral centre of $\mathrm{C}_{1}$ of $\mathrm{N}$-methylisosalsoline is Rectus (Figure).

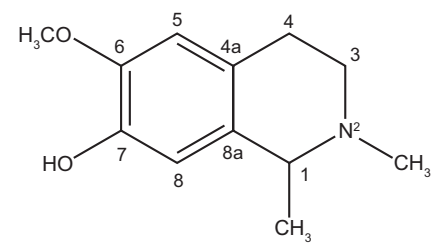

1: $\mathrm{R}=\mathrm{CH}_{3}$ carnegine; $2: \mathrm{R}=\mathrm{H} N$-methylisosalsoline.

Adult G. truncatula (3-5 $\mathrm{mm}$ in length) were collected locally from a drainage canal located in Tozeur's traditional oasis, in February 2007. They were transferred to laboratory aquaria and acclimatised for a minimum of four days in holding tanks containing aerated, dechlorinated tap water and washed sand. They were then exposed to aqueous solutions of the extracts. The toxicity of these preparations was also tested on G. truncatula control organisms.

Evaluation of the molluscicidal activity of the $H$. scoparia extracts and $\mathrm{CuCl}_{2}$ (used as positive control) against snails was investigated as recommended by the WHO (1965). A series of aqueous solutions to be used in the bioassays was prepared from each of the four extracts, hexane, dichloromethane, methanol and $\mathrm{EtOH}-$ $\mathrm{H}_{2} \mathrm{O}$, respectively. Each series consisted of 20 solutions containing amounts ranging from 5-100 $\mathrm{mg}$ of extract material in $5 \mathrm{mg}$ increments. The same method was adopted for the preparation of each concentration of the extracts A, B and C obtained from the methanol extract. For the pure products, the weights ranged from $0.1-1 \mathrm{mg}$ of $\mathrm{N}$-methylisosalsoline or carnegine in increments of $0.1 \mathrm{mg}$. For $\mathrm{CuCl}_{2}$, the weights ranged from $1-20 \mathrm{mg}$ in 1 $\mathrm{mg}$ increments. We added sufficient dechlorinated water to each amount of extract material to give a final volume of $1000 \mathrm{~mL}$. Each solution was divided into equal volumes of $500 \mathrm{~mL}$. For each test, we used a control of dechlorinated water without extract, having the same volume as the test solution.

The snails were exposed in groups of 10 (5 replicates) for $48 \mathrm{~h}$ (exposure period) to $500 \mathrm{~mL}$ of each concentration of one of the materials to be tested: extracts, fractions and products or $\mathrm{CuCl}_{2}$ (the positive control used in each case), as shown in Tables I and II. G. truncatula negative control organisms were immersed in dechlorinated water. After exposure, snails were rinsed thoroughly in dechlorinated water and left for $48 \mathrm{~h}$ in dechlorinated water (recovery period) before mortality was evaluated. Mortality was recorded after $48 \mathrm{~h}$ and dead animals were removed immediately to avoid contamination of live animals. Snail mortality was established by the contraction of the body into the shell. No response to a needle probe was taken as evidence of death.

The concentrations that killed $50 \%\left(\mathrm{LC}_{50}\right)$ or $90 \%$ $\left(\mathrm{LC}_{90}\right)$ of the exposed snails and the confidence interval $(95 \% \mathrm{CI})$ were determined by the R language analysis, which is an integrated suite of software facilities for data manipulation, calculation and graphical display (Ihaka \& Gentleman 1996, Venables et al. 2004).

The molluscicidal activity of $H$. scoparia leaf extracts and $\mathrm{CuCl}_{2}$ against $G$. truncatula (Table I) was highest for the methanol extract $\left(\mathrm{LC}_{50}=28.93 \mathrm{ppm}, \mathrm{LC}_{90}=\right.$ $69.96 \mathrm{ppm}$ ), next highest for the dichloromethane extract $\left(\mathrm{LC}_{50}=33.90 \mathrm{ppm}, \mathrm{LC}_{90}=74.67 \mathrm{ppm}\right)$ and lowest for the ethanol-water extract $\left(\mathrm{LC}_{50}=46.87 \mathrm{ppm}, \mathrm{LC}_{90}=72.10\right.$ $\mathrm{ppm})$. Cupric chloride at $11.34 \mathrm{ppm}$ induced the death of $90 \%$ of molluscs after six days of treatment (Table I). Chemical tests performed on the extracts for alkaloids were positive, particularly for the methanol extract, followed by the ethanol- $\mathrm{H}_{2} \mathrm{O}$ extract. The hexane extract was inactive against $G$. truncatula and did not contain alkaloids.

The molluscicidal activities of extracts A, B and C, obtained after acid-base treatment of the methanol extract, the fractions obtained by column chromatography and the purified alkaloids are reported in Table II. Molluscicidal activity was not observed for extracts $\mathrm{A}$ and $\mathrm{C}$ and was concentrated in extract B (total alkaloids). Fractions 1-5, obtained from extract $B$ were inactive. These fractions contained carnegine and other minor alkaloids. The molluscicidal activity reappeared in fraction 6, in which $N$-methylisosalsoline started to be eluted from the column and increased in fraction 7 , in which pure $N$-methylisosalsoline was eluted $\left(\mathrm{LC}_{50}=0.47 \mu \mathrm{M}\right.$ $\mathrm{LC}_{90}=0.86 \mu \mathrm{M}$ after $48 \mathrm{~h}$ ). Then, the molluscicidal activity decreased gradually in fractions 8 and 9 and disappeared in the last fractions. G. truncatula control organisms were not affected by dechlorinated water after $48 \mathrm{~h}$ exposure.

The prevention of fasciolosis is difficult, despite the efficiency of the measures taken. Chemical molluscicides such as sulphate, copper chloride and the Bayluscides are known to have a strong lethal effect on invasive mollusc species (Rondelaud 1986, Claudi \& Mackie 1994, Kennedy et al. 2006). It has been realised, however, that these molluscicides are toxic to non-target animals and have a long-term detrimental effect on aquatic environments (Andrews et al. 1983, Singh et al. 1996). Several plant products with molluscicidal activity against the genus Lymnaea have been reported. An aqueous solution of the latex of Euphorbia splendens var. hisloppi with molluscicidal activity against Lymnaea columella has been reported in laboratory $\left(\mathrm{LC}_{90}=0.55 \mathrm{mg} / \mathrm{L}\right)$ and in field conditions (Vasconcellos \& Amorim 2003a, b).

H. scoparia is a highly branched, halophytic shrub distributed in Southeast of Tunisia, Spain and parts of Turkey, Iran, Syria and Iraq (Irano-Turanian Region) (Maire 1962, Jafri \& Rateeb 1978, Pottier-Alapetite 1981, Greuter et al. 1984). An aqueous extract of this plant has been reported to possess larvicidal (Sathiamoorphy et al. 1997), anti-cancer and anti-plasmodial activities (Sathiamoorphy et al. 1999). The molluscicidal activity of $H$. scoparia has not previously been reported.

During our study, of the four $H$. scoparia leaf extracts, three showed significant molluscicidal activity. However, 
only two extracts, the dichloromethane extract and the methanol extract, gave $\mathrm{LC}_{50}$ values $(33.90 \mathrm{ppm}$ and 28.93 ppm, respectively) against $G$. truncatula, where these fell well below the upper threshold of $40 \mathrm{ppm}$ (WHO 1993). The analyses of $H$. scoparia extracts showed that the methanol one was the richest in alkaloids and the most active against $G$. truncatula $\left(\mathrm{LC}_{50}=28.93 \mathrm{ppm}\right)$, so al- kaloid content may correlate with molluscicidal activity. The predominant alkaloids isolated, carnegine 1 and $N$ methylisosalsoline 2, are isoquinolines that have not previously been characterised for their molluscicidal activity. The results obtained indicated that the $\mathrm{N}$-methylisosalsoline $2\left(\mathrm{LC}_{50}=0.47 \mu \mathrm{M}\right)$ possessed the highest molluscicidal activity against the snails, after $48 \mathrm{~h}$, compared with

TABLE I

Molluscicidal activities of Hammada scoparia leaf extracts against Galba truncatula

\begin{tabular}{|c|c|c|c|c|c|}
\hline \multirow[b]{2}{*}{ Extract } & \multicolumn{2}{|c|}{ After $24 \mathrm{~h}$ action } & \multicolumn{2}{|c|}{ After $48 \mathrm{~h}$ action } & \multirow[b]{2}{*}{ Alkaloids } \\
\hline & $\begin{array}{c}\mathrm{LC}_{50}(\mathrm{ppm}) \\
(95 \% \mathrm{CI})\end{array}$ & $\begin{array}{c}\mathrm{LC}_{90}(\mathrm{ppm}) \\
(95 \% \mathrm{CI})\end{array}$ & $\begin{array}{c}\mathrm{LC}_{50}(\mathrm{ppm}) \\
(95 \% \mathrm{CI})\end{array}$ & $\begin{array}{c}\mathrm{LC}_{90}(\mathrm{ppm}) \\
(95 \% \mathrm{CI})\end{array}$ & \\
\hline EtOH-H ${ }_{2} \mathrm{O}(1-9, \mathrm{v}-\mathrm{v})$ & $\begin{array}{c}77.65 \\
(73.46 ; 81.83)\end{array}$ & $\begin{array}{c}96.87 \\
(83.52 ; 110.23)\end{array}$ & $\begin{array}{c}46.87 \\
(42.38 ; 51.22)\end{array}$ & $\begin{array}{c}72.10 \\
(64.44 ; 85.74)\end{array}$ & ++ \\
\hline Hexane & $\begin{array}{c}82.75 \\
(71.76 ; 137.72)\end{array}$ & $\begin{array}{c}122.21 \\
(92.90 ; 383.26)\end{array}$ & $\begin{array}{c}82.75 \\
(71.76 ; 137.72)\end{array}$ & $\begin{array}{c}122.21 \\
(92.89 ; 383.26)\end{array}$ & - \\
\hline $\mathrm{CH}_{2} \mathrm{Cl}_{2}$ & $\begin{array}{c}33.99 \\
(23.17 ; 41.47)\end{array}$ & $\begin{array}{c}89.64 \\
(66.45 ; 274.71)\end{array}$ & $\begin{array}{c}33.90 \\
(11.38 ; 45.57)\end{array}$ & $\begin{array}{c}74.67 \\
(59.42 ; 125.87)\end{array}$ & ++ \\
\hline $\mathrm{MeOH}$ & $\begin{array}{c}31.68 \\
(23.89 ; 39.48)\end{array}$ & $\begin{array}{c}75.96 \\
(64.49 ; 87.43)\end{array}$ & $\begin{array}{c}28.93 \\
(21.36 ; 36.50)\end{array}$ & $\begin{array}{c}69.96 \\
(59.52 ; 80.41)\end{array}$ & +++ \\
\hline Dechlorinated water & 0 & 0 & 0 & 0 & - \\
\hline
\end{tabular}

the $\mathrm{CuCl}_{2}$ showed molluscicidal activity against the mollusca gastropoda G. truncatula only after $144 \mathrm{~h}$ with: $\mathrm{LC}_{50}=6.20(5.42$; $6.94) \mathrm{ppm}$ and $\mathrm{LC}_{90}=11.34 \mathrm{ppm}$. CI: confidence interval; $\mathrm{LC}_{50}: 50 \%$ lethal concentration; $\mathrm{LC}_{90}: 90 \%$ lethal concentration; ++: presence; +++: richness; -: not detected.

TABLE II

Molluscicidal activities of Hammada scoparia leaf extracts after acido-basic treatment of the methanolic extract, its fractions and their major isolated alkaloids against Galba truncatula

\begin{tabular}{|c|c|c|c|c|c|}
\hline \multirow[b]{2}{*}{ Extracts } & \multirow[b]{2}{*}{ Fraction of extract B } & \multicolumn{2}{|c|}{ After $24 \mathrm{~h}$ action } & \multicolumn{2}{|c|}{ After $48 \mathrm{~h}$ action } \\
\hline & & $\begin{array}{l}\mathrm{LC}_{50}(\mathrm{ppm}) \\
(95 \% \mathrm{CI})\end{array}$ & $\begin{array}{c}\mathrm{LC}_{90}(\mathrm{ppm}) \\
(95 \% \mathrm{CI})\end{array}$ & $\begin{array}{c}\mathrm{LC}_{50}(\mathrm{ppm}) \\
(95 \% \mathrm{CI})\end{array}$ & $\begin{array}{c}\mathrm{LC}_{90}(\mathrm{ppm}) \\
(95 \% \mathrm{CI})\end{array}$ \\
\hline $\mathrm{A}$ and $\mathrm{C}$ & & 0 & 0 & 0 & 0 \\
\hline \multirow[t]{9}{*}{ B } & & $\begin{array}{c}37.53 \\
(32.29 ; 43.01)\end{array}$ & $\begin{array}{c}50.40 \\
(43.76 ; 74.80)\end{array}$ & $\begin{array}{c}29.51 \\
(22.47 ; 34.96)\end{array}$ & $\begin{array}{c}49.25 \\
(41.30 ; 67.65)\end{array}$ \\
\hline & Fraction 1-2 & 0 & 0 & 0 & 0 \\
\hline & Fraction 3 (carnegine) & 0 & 0 & 0 & 0 \\
\hline & Fraction 4-5 & 0 & 0 & 0 & 0 \\
\hline & Fraction 6 & $\begin{array}{c}0.38 \\
(0.31 ; 1.01)\end{array}$ & $\begin{array}{c}0.66 \\
(0.45 ; 17.33)\end{array}$ & $\begin{array}{c}0.22 \\
(0.07 ; 0.71)\end{array}$ & $\begin{array}{c}0.52 \\
(0.05 ; 5.19)\end{array}$ \\
\hline & $\begin{array}{c}\text { Fraction } 7 \\
(N \text {-methyl isosalsoline) }\end{array}$ & $\begin{array}{c}0.27 \\
(0.21 ; 0.35)\end{array}$ & $\begin{array}{c}0.47 \\
(0.36 ; 1.13)\end{array}$ & $\begin{array}{c}0.098 \\
(0.084 ; 0.122)\end{array}$ & $\begin{array}{c}0.18 \\
(0.14 ; 0.31)\end{array}$ \\
\hline & Fraction 8 & $\begin{array}{c}0.43 \\
(0.15 ; 1.28)\end{array}$ & $\begin{array}{c}1.51 \\
(0.20 ; 11.37)\end{array}$ & $\begin{array}{c}0.29 \\
(0.16 ; 0.51)\end{array}$ & $\begin{array}{c}1.00 \\
(0.08 ; 12.29)\end{array}$ \\
\hline & Fraction 9 & $\begin{array}{c}0.75 \\
(0.19 ; 2.88)\end{array}$ & $\begin{array}{c}2.49 \\
(0.15 ; 41.36)\end{array}$ & $\begin{array}{c}0.31 \\
(0.17 ; 0.55)\end{array}$ & $\begin{array}{c}1.49 \\
(0.22 ; 10.24)\end{array}$ \\
\hline & Fraction $10-11$ & 0 & 0 & 0 & 0 \\
\hline Dechlorinated water & & 0 & 0 & 0 & 0 \\
\hline
\end{tabular}

CI: confidence interval; $\mathrm{LC}_{50}: 50 \%$ lethal concentration; $\mathrm{LC}_{90}: 90 \%$ lethal concentration. 
other products tested, while carnegine was found to be inactive. It is likely that the phenolic function of the $N$ methylisosalsoline contributes to molluscicidal activity.

In our study, the $N$-methylisosalsoline was more active than the cupric chloride, which showed activity only after $144 \mathrm{~h}\left(\mathrm{LC}_{90}=11.34 \mathrm{ppm}\right)$. A comparison with synthetic molluscicides, such as niclosamide $\left(\mathrm{LC}_{90}=0.45 \mathrm{ppm}\right)$ and nicotinanilide $\left(\mathrm{LC}_{90}=1.39 \mathrm{ppm}\right)$, used against Lymnaea luteola (Sukumaran et al. 2004), showed that N-methylisosalsoline had comparable molluscicidal activity after $24 \mathrm{~h}$. According to the World Health Organization's guidelines on screening for plant molluscicides (WHO 1983), isolation of the molluscicidal compound $\mathrm{N}$-methylisosalsoline from $H$. scoparia may add to the arsenal of methods to control snails that transmit fasciolosis in tropical and third world countries, where fasciolosis is a common disease.

\section{REFERENCES}

Ahmed AH, Rifaat MM 2004. Molluscicidal and cercaricidal efficacy of Acanthus mollis and its binary and tertiary combinations with Solanum nigrum and Iris pseudacorus against Biomphalaria alexandrina. J Egypt Soc Parasitol 34: 1041-1050.

Andrews P, Thyssen J, Lorke D 1983. The biology and toxicology of molluscicides, Bayluscide ${ }^{\circledR}$. Pharmacol Therap 19: 245-295.

Ayadi A, Makni F, Ben Saïd M 1997. Etat actuel de la fasciolose en Tunisie. Bull Soc Fr Parasitol 15: 27-32.

Benkrief R, Brum-Bousquet M, Tillequin F, Koch M 1990. Alkaloids and flavonoid from aerial parts of Hammada articulata spp scoparia. Ann Pharmac Fr 48: 219-224.

Carling C, Sandberg F 1970. Alkaloids of Haloxylon articulatum. Acta Pharmacol Suecica 7: 285-288.

Claudi R, Mackie GL 1994. Practical manual for zebra mussel monitoring and control, CRC Press, Boca Raton, $227 \mathrm{pp}$.

El-Ansary A, Mohamed AM, Mahmoud SS, El-Bardicy S 2003. On the pathogenicity of attenuated Schistosoma mansoni cercariae released from metabolically disturbed Biomphalaria alexandrina.J Egypt Soc Parasitol 33: 777-794.

Greuter W, Burdel MH, Long G 1984. Med-checklist, a critical inventory of vascular plants of the Circum-Mediterranean Countries, vol. 1, Edition des Conservatoire et Jardin Botaniques de la Ville de Genève, Genève, $304 \mathrm{pp}$.

Hammami H, Ayadi A 1999. Ecologie de Lymnaea truncatula Muller, hôte intermédiaire de Fasciola hepatica Linné dans le microclimat de Tozeur (sud-ouest de la Tunisie). Bul Soc Pathol Exot 92: 302-304.

Hammami H, Hamed N, Ayadi A 2007. Epidemiological studies on Fasciola hepatica in Gafsa oases (Southwest of Tunisia). Parasite 14: 261-264.

Ihaka R, Gentleman R 1996. R: a language for data analysis and graphics. J Comput Graph Stat 3: 299-314.

Jafri SMH, Rateeb FB 1978. Flora of Lybia. 58. Chenopodiaceae, Al Faateh University, Tripoli, p. 88-95.

Jarraya MR, Bouaziz A, Hamdi B, Ben Salah A, Damak M 2008. $\mathrm{N}$-methylisosalsoline from Hammada scoparia. Acta Cryst E 64: o1714.

Jarraya R, Chaieb M, Damak M 1993. Screening des plantes à alcaloïdes au sein de la flore Tunisienne. Plant Med Phytotherapy 26: $177-189$.
Jarraya R, Damak M 2001. Alkaloids extracted from the leaves of Hammada scoparia (Pomel) Iljin. J Soc Chim Tunisie 4: 941-948.

Kennedy AJ, Millward RN, Steevens JA, Lynn JW, Perry KD 2006. Relative sensitivity of zebra mussel (Dreissena polymorpha) life stages to two copper sources. J Great Lakes Res 32: 363-369.

Maire R 1962. Flore de l'Afrique du Nord, vol. 8, Editions Paul Le chevalier, Paris, p. 161-164.

Mas-Coma S, Funatsu IR, Bargues MD 2001. Fasciola hepatica and Lymnaeid snails occurring at very high altitude in South America. Parasitology 123: 115-127.

Melendez PA, Capriles VA 2002. Molluscicidal activity of plants from Puerto Rico. Ann Trop Med Parasitol 96: 209-218.

Pottier-Alapetite G 1981. Flore de la Tunisie Angiospermes-Dicotylédones Gamopétales, Imprimerie Officielle de la République Tunisienne, Tunis, $821 \mathrm{pp}$.

Rondelaud D 1986. Le contrôle mixte et alterné de Lymnaea truncatula Müller par voie chimique et biologique. Premiers essais expérimentaux sur le terrain. Ann Rech Vet 17: 15-20.

Sathiamoorthy P, Lugasi-Evgi H, Schlesinger P, Kedar I, Gopas J, Pollack Y, Golan-Goldhirsh A 1999. Screening for cytotoxic and antimalarial activities in desert plants of the Negev and Bedouin market plant products. Pharmaceutical Biol 35: 18-195.

Sathiamoorthy P, Lugasi-Evgi H, Van-Damme P, Abu-Rabia A, Gopas J, Golan-Goldhirsh A 1997. Larvicidal activity in desert plants of the Negev and Bedouin market plant products. Int J Pharmacol 35: $265-273$.

Silva TM, Camara CA, Agra M de F, De Carvalho MG, Frana MT, Brandoline SV, Da Silva Paschoal L, Braz-Filho R 2006. Molluscicidal activity of Solanum species of the Northeast of Brazil on Biomphalaria glabrata. Fitoterapia 77: 449-452.

Singh A, Singh DK, Misra TN, Agarwal RA 1996. Molluscicides of the plant origin. Biol Agric Hortic 13: 205-252.

Sukumaran D, Parashar BD, Gupta AK, Jeevaratnam K, Prakash S 2004. Molluscicidal effect of nicotinanilide and its intermediate compounds against a freshwater snail Lymnaea luteola, the vector of animal schistosomiasis. Bioline International. Mem Inst Oswaldo Cruz 99: 205-210.

Vasconcellos MC, Amorim A 2003a. Molluscicidal action of the latex of Euphorbia splendens var. hisloppi N.E.B. ("Christ's Crown") (Euphorbiaceae) against Lymnaea columella (Say, 1817) (Pulmonata: Lymnaeidae), intermediate host of Fasciola hepatica Linnaeus, 1758 (Trematoda: Fasciolidae). 1. Test in laboratory. Mem Inst Oswaldo Cruz 98: 557-563.

Vasconcellos MC, Amorim A 2003b. Activity of Euphorbia splendens var. hisloppi N.E.B. (Euphorbiaceae) against Lymnaea columella (Say, 1817) (Pulmonata: Lymnaeidae), intermediate host of Fasciola hepatica Linnaeus, 1758 (Trematoda: Fasciolidae). 2. Limited field-testing. Mem Inst Oswaldo Cruz 98: 981-985.

Venables WN, Smith DM, the R. Development Core Team 2004. An introduction to R. version 1.9.1. Available from: http://www.rproject.org/.

WHO - World Health Organization 1965. Molluscicide screening and evaluation. Bull WHO 33: 567-581.

WHO - World Health Organization 1983. Report of the scientific working group on plant molluscicides, Document WHO/TDR/ SCH-SWE 4, 83.3, WHO, Geneva, 1-11.

WHO - World Health Organization 1993. Tropical disease research, The control of Schistosomiasis. Tech Rep Ser 830: 1-86. 